\title{
PENGEMBANGAN PERANGKAT LABORATORIUM DENGAN APLIKASI INTERFACING SENSOR CAHAYA DENGAN STOPWATCH PADA PERISTIWA GERAK PARABOLA
}

\author{
Stepanus Sahala S. \\ Jurusan PMIPA, Prodi Pend. Fisika FKIP UNTAN \\ Email
}

\begin{abstract}
This research has the objective of knowing the application of light concept as a sensor in the moment of projectile motion using the aplication of light sensor interfacing in stopwatch. The making of light sensor device is with electronic circuits method, while the defeniting the time uses digital stopwatch. Both devices are combined to be instrument of projectile motion experiment. The result of data analysis from the graphic, the distance of the time line the curve, that it is achieved a relationship between the variable and gradient or the degree of the graphic slope of the line is 4,875. From the calculation the gradient got gravitational acceleration $(g)$ that is 9,75 $\mathrm{m} / \mathrm{s}^{2}$. Gravitational acceleration that is almost reading the standard gravitational acceleration, that is $9,8 \mathrm{~m} / \mathrm{s}^{2}$ and it has only $0,05 \mathrm{~m} / \mathrm{s}^{2}$ in difference from the research. It proves that this device can work well and stopwatch can automatically work.
\end{abstract}

Keywords: Interfacing light sensor, motion projectile.

Fisika merupakan dasar perkembangan kemajuan teknologi. Ilmu fisika memberi andil yang sangat besar dalam pesatnya kemajuan teknologi (Giancoli, 1998). Banyak peralatan-peralatan (sistemsistem) yang telah dirancang dan dibuat untuk menunjang perkembangan teknologi yang dalam perancangan dan pembuatannya tidak sekedar memenuhi saja, tetapi lebih dituntut ketelitian (Soejoto dan Euis Sutini, 1993). Pada percobaan gerak parabola yang menggunakan stopwatch untuk menghitung waktu benda jatuh bebas, hasil yang diperoleh kurang begitu akurat dan tepat, sehingga dengan interfacing sensor cahaya pada stopwatch secara otomatis perhitungan waktu benda jatuh dapat langsung terbaca dan hasil yang diperoleh lebih akurat dan tepat dibandingkan dengan menggunakan stopwatch untuk menghitung waktu benda saat berada pada posisi tertinggi dan kembali ke tanah.

Penelitian ini dilakukan untuk mengetahui bentuk konfigurasi sensor cahaya dengan peristiwa gerak parabola. Dengan membuat peralatan sensor cahaya suatu rangkaian digital (Cooper, 1978), yang dikaitkan dengan gerak parabola akan memperoleh hasil yang lebih akurat. Dengan adanya interfacing sensor cahaya pada stopwatch secara otomatis perhitungan waktu benda berada pada posisi tertinggi dan saat kembali ke tanah dapat langsung 
terbaca. Pembuatan alat sensor cahaya dilakukan dengan metode rangkaian elektronik, sedangkan penentuan waktu menggunakan stopwatch digital (Sumisjo, 1998), kemudian kedua peralatan tersebut dihubungkan rangkaian dari peralatan gerak parabola.

Penelitian ini penting dilakukan, berdasarkan publikasi ilmiah, pemanfaatan alat konfigurasi sensor cahaya dapat diaplikasikan pada eksperimen/percobaan gerak parabola. Rangkaian interfacing dalam penelitian ini menggunakan LED inframerah sebagai pemancar dan fototransistor sebagai penerimanya (Cooper, 1978). Rangkaian ini juga menggunakan Integrate Circuit (IC) yang berfungsi sebagai saklar dua sisi/bilateral, atau berempat (Warsito, 1982). Penggunaan LED infraredmerah dikarenakan LED jenis ini lebih sensitif dari pada LED sinar tampak dan LED inframerah lebih stabil terhadap gangguan-gangguan sekelilingnya (Malvino, 1979).

IC mempunyai resistansi yang sangat tinggi pada keadaan off dan resistansi yang sangat rendah pada keadaan on (Faulkenberry, Luces, 1982), hal ini melindungi stopwatch dari pentrigeran rangkaian yang mungkin terjadi karena penggunaan tegangan yang tidak sesuai (Sumual, 1988). Rangkaian ini juga cocok untuk beberapa macam stopwatch yang diproduksi oleh pabrik yang berbeda. Jadi hanya diperlukan sedikit modifikasi pada stopwatch jika ingin menggunakan rangkaian ini. Dilakukannya konfigurasi sensor cahaya melalui pembuatan peralatan sensor cahaya menggunakan suatu rangkaian elektronik yang kemudian dikaitkan dengan gerak parabola sehingga diperoleh hasil yang dapat meminimalisasi keakuratan dan ketepatan perhitungan waktu ketika benda berada pada posisi tertinggi hingga kembali ke tanah (Amin, 1988). Penelitian ini dapat dijadikan salah satu metode baru dalam melakukan eksperimen/percobaan gerak parabola.

\section{Metode}

\section{Desain Alat}

Rangkaian elektronik alat ini relatif sederhana dan digunakan untuk percobaan gerak parabola, maka desain alat menjadi amat penting untuk diperhatikan (Armitage,1982). Alat ini dibuat cukup kecil dan praktis sehingga dapat dimasukkan ke dalam kotak kecil yang mudah dipindahpindahkan, sedangkan stopwatch diletakkan di atas kotak tersebut, sehingga yang terlihat dari luar adalah sebuah kotak kecil dan stopwatch.

Selain itu yang terpenting adalah mendesain bentuk sensor inframerah agar mudah digunakan untuk melakukan percobaan, hal yang perlu diperhatikan dalam mendesain bentuk sensor adalah alat ini diletakkan pada tabung peluncur dan pada lintasan gerak parabola. Sensor I dibuat statis di ujung tabung peluncur, sedangkan sensor II dapat diubahubah, selanjutnya peletakkan dan jarak antara diode pemancar inframerah dan phototransistor penerima inframerah juga harus diatur sedemikian rupa agar sensor dapat bekerja secara optimal dan sensor dapat dilewati oleh benda yang menjadi objek dalam gerak parabola.

Akhirnya diputuskan untuk membuat tempat sensor yang berbentuk seperti huruf A, karena 
dengan bentuk seperti ini akan memudahkan benda melalui sensor tersebut dan sensor akan mudah untuk dijepit dan digeser-geser kedudukannya pada statip. Sensor yang digunakan adalah berupa diode dan phototransistor yang dikemas menjadi satu bentuk seperti huruf A. Bentuk seperti ini tentu tidak akan dapat digunakan untuk percobaan yang dilakukan, maka dilakukan pemotongan sensor tersebut dan memisahkan diode pemancar dengan phototransistornya.

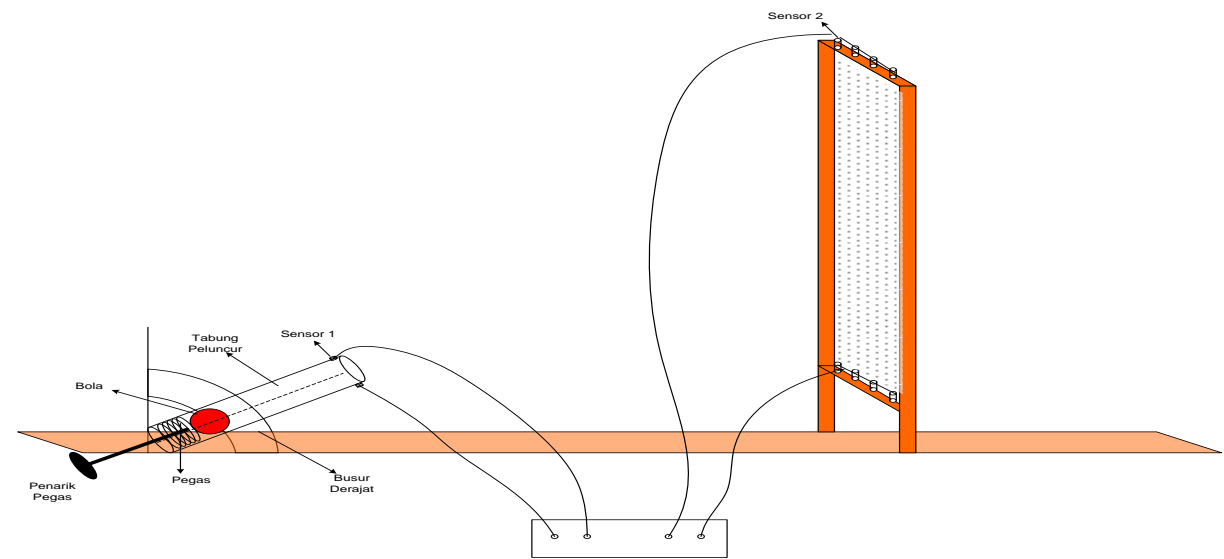

Gambar 1. Prototipe Alat Percobaan Gerak Parabola.

2. Cara Kerja Alat dibuat adalah seperti pada Gambar Rangkaian elektronik alat yang 2 di bawah ini.

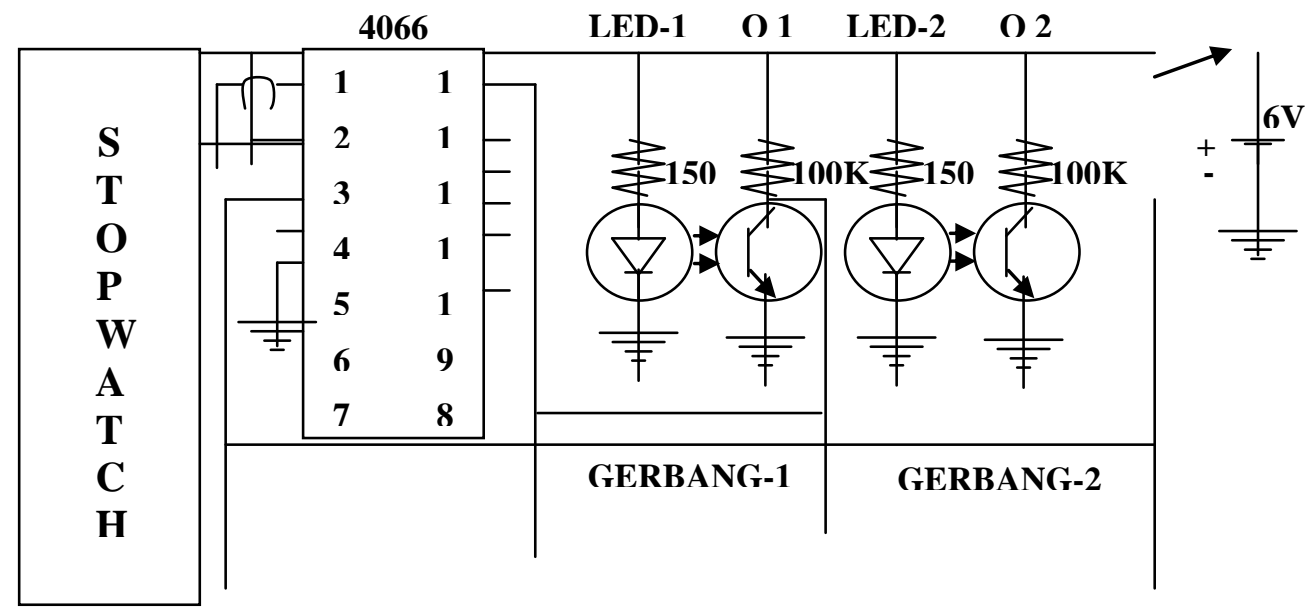

Gambar 2 Rangkaian Dasar Elektronik Alat Gerak Parabola.

Rangkaian tersebut terdiri dari dua gate (gerbang), yaitu gate 1 dan gate 2. Gate 1 merupakan gate start dan gate 2 merupakan gate stop. Kedua gate tersebut masing-masing terdiri dari LED infrared dan phototransistor. Pada Gambar 2, ketika rangkaian dihubungkan dengan 
sumber tegangan maka LED di kedua gerbang akan menyala. LED yang menyala ini memancarkan cahaya inframerah yang kemudian diterima oleh phototransistor, hal ini menyebabkan tegangan diphototransistor mendekati nol dan pada saat ada benda lewat di gate 1, maka tegangan diphototransistor besarnya akan mendekati besar sumber tegangan. Jadi pada saat benda melewati gate 1 , ada pulsa yang dikirim untuk menghitung, hal yang sama terjadi pada gate 2, tetapi pada gate 2 pulsa yang dikirim oleh phototransistor akan menghentikan stopwatch yang sedang menghitung waktu.

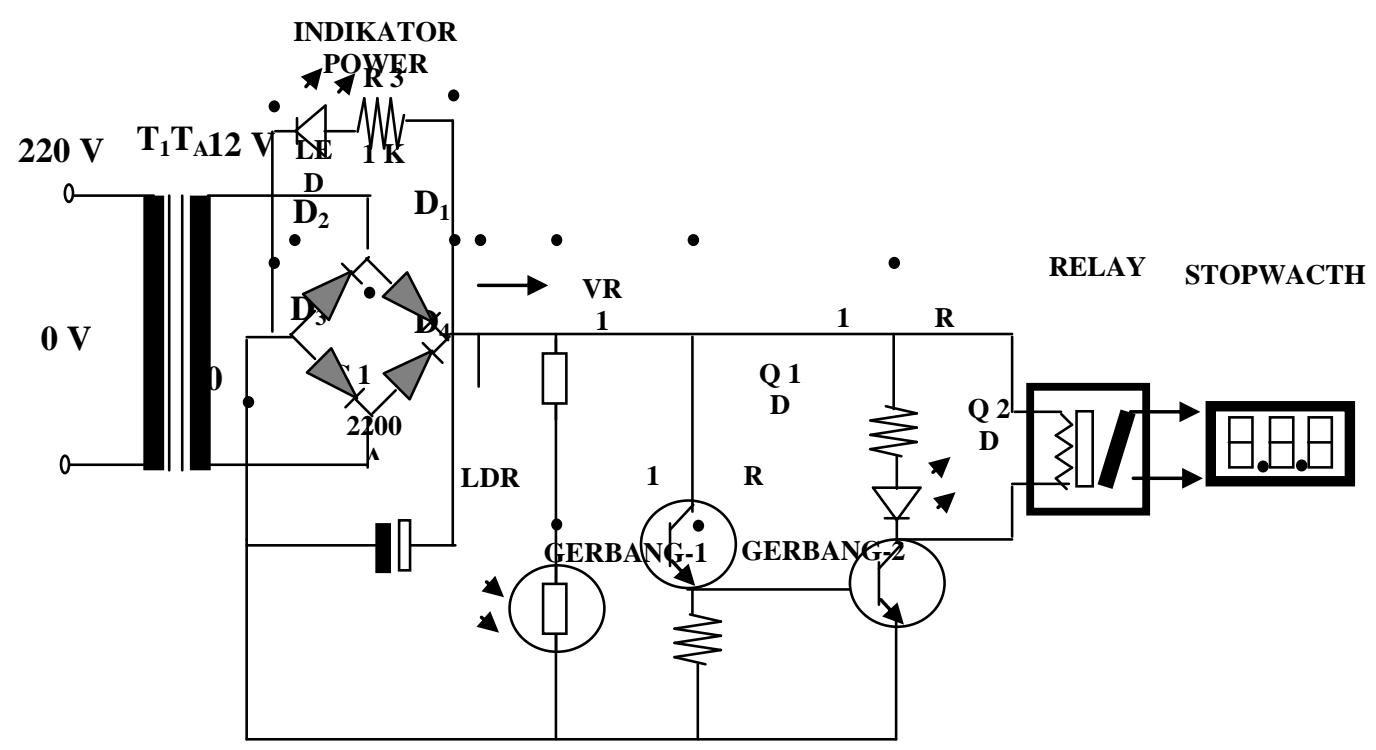

Gambar 3 Rangkaian Alat Lengkap Gerak Parabola.

Berdasarkan cara kerja inilah maka dapat diukur waktu tempuh benda yang dijatuhkan dan melewati kedua sensor tersebut. Karena dapat diukur waktu dan jarak yang dilewati benda tersebut maka dapat diukur besarnya percepatan gravitasi berdasarkan persamaan:

$$
H-H_{o}=V_{o} t+1 / 2 g t^{2}
$$

3. Pengambilan dan Pengolahan Data

Pengambilan data dilakukan dengan cara melepaskan perangkat penembak pegas, sehingga bola dari atas sensor pertama mencatat waktu yang tertera pada stopwatch, sampai bola tersebut melewati sensor kedua. Data yang diambil sebanyak 5 kali untuk tiap-tiap sudut kemiringan penembak/meriam. Variasi sudut dapat diubah-ubah, yaitu dengan cara menggeser posisi penembak sesuai sudut tertentu.

Metode pengolahan data dari percobaan yang dilakukan adalah dengan menggunakan metode kuadrat terkecil. Metode ini mengolah data dengan cara memvisualisasikan data dalam bentuk grafik atau kurva dari variabel yang di kehendaki (Nasir, 2009).

Tujuan dibuatnya grafik pada metode ini adalah:

1. Melihat hubungan antara variabel.

2. Menghitung konstanta atau koefisien dari rumus. 
Untuk keperluan nomor 1, yaitu melihat hubungan antar variabel, dilakukan dengan cara membuat/memplot semua titik data pada grafik dan mencari pola dari titik-titik data yang ada (dibuat garis lurus atau garis lengkung), sedangkan untuk keperluan nomor 2, yaitu untuk menghitung konstanta atau koefisien rumus maka diusahakan agar kurva berbentuk fungsi linier.

\section{Hasil dan Pembahasan}

Hasil data yang diperoleh dengan cara menembakkan bola yang terlebih dahulu ditentukan sudut kemiringan penembak meriam dan selanjutnya menentukan waktu serta jarak jangkauan tembakan. Data-data yang dihasilkan disajikan pada Tabel 1.

Tabel 1 Hasil Data Penelitian.

\begin{tabular}{cccccccccccc}
\hline \multirow{2}{*}{ No } & \multirow{2}{*}{ Sudut ( $\left(^{0}\right)$} & \multicolumn{4}{c}{ Waktu (t) sekon } & \multicolumn{5}{c}{ Jarak jangkauan (R) meter } \\
\cline { 2 - 12 } & 1 & 2 & 3 & 4 & 5 & 1 & 2 & 3 & 4 & 5 \\
\hline 1 & $30^{\circ}$ & 0,48 & 0,48 & 0,48 & 0,48 & 0,48 & 1,536 & 1,536 & 1,536 & 1,536 & 1,536 \\
\hline 2 & $45^{\circ}$ & 0,56 & 0,56 & 0,56 & 0,56 & 0,56 & 1.568 & 1.568 & 1.568 & 1.568 & 1.568 \\
\hline 3 & $60^{\circ}$ & 0,64 & 0,64 & 0,64 & 0,64 & 0,64 & 1,536 & 1,536 & 1,536 & 1,536 & 1,536 \\
\hline
\end{tabular}

Tabel 2 Kecepatan Rata-rata $(\bar{V})$

\begin{tabular}{ccccc}
\hline No & $\begin{array}{c}\text { Sudut } \\
\left(^{\mathbf{0}}\right)\end{array}$ & $\begin{array}{c}\text { Waktu }(\bar{t}) \\
\text { sekon }\end{array}$ & $\begin{array}{c}\text { Jarak Jangkauan }(\mathbf{R}) \\
\text { meter }(\mathbf{m})\end{array}$ & $\begin{array}{c}\text { Kecepatan Rata-rata }(\bar{V}) \\
\text { meter/sekon }(\mathbf{m} / \mathbf{s})\end{array}$ \\
\hline 1 & $30^{\circ}$ & 0,48 & 1,51 & 3,14 \\
\hline 2 & $45^{\circ}$ & 0,56 & 1.54 & 2.76 \\
\hline 3 & $60^{\circ}$ & 0,64 & 1,51 & 2.36 \\
\hline
\end{tabular}

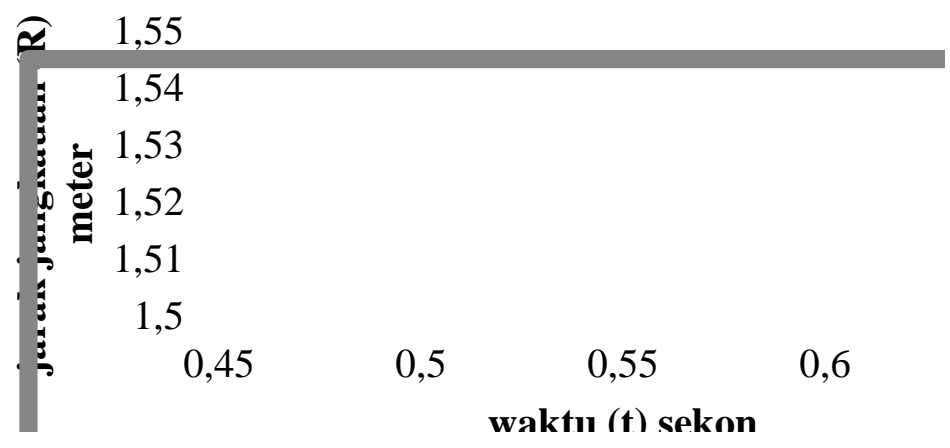

Gambar 4 Grafik Hubungan Jarak (s) terhadap Waktu (t) 


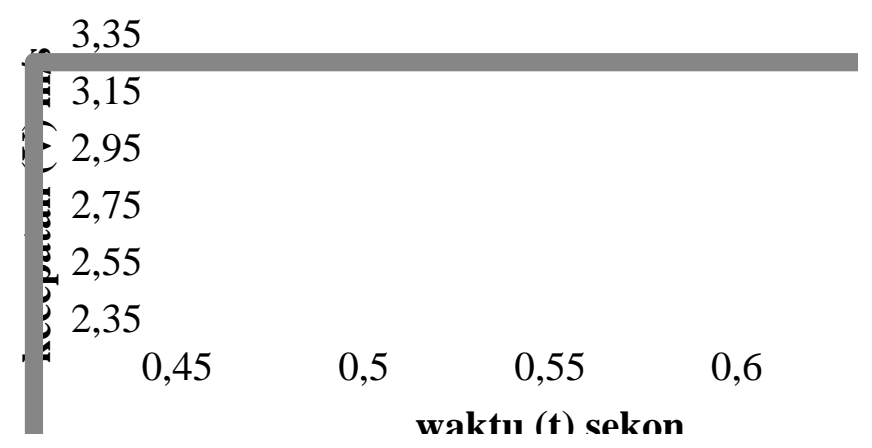

Gambar 5 Grafik Hubungan Kecepatan (V) terhadap Waktu (t)

Perhitungan Gradien pada grafik sebagai berikut:

$$
\begin{aligned}
& m=\frac{\Delta v}{\Delta t}=\frac{v_{t}-v_{0}}{t-t_{0}} \\
& m=\frac{2,36-3,14}{0,48-0,64}=\frac{-0,78}{-0,16}=4,875 \\
& m=\frac{1}{2} g \\
& g=2 m \\
& g=2 x 4,875=9,75 m / s^{2}
\end{aligned}
$$

Aplikasi interfacing sensor cahaya pada stopwatch pada percobaan gerak parabola berfungsi sebagai alat untuk menghitung waktu benda jatuh secara otomatis khususnya pada gerak para bola. Berdasarkan fungsi alat dan rangkaian yang dibuat ternyata setelah berulang kali dilakukan uji coba, rangkaian yang menggunakan IC 4066 memiliki sensitifitas yang sangat peka sehingga berpengaruh terhadap rangsangan angin dan intensitas cahaya. Pada saat angin bertiup alatnya bekerja secara otomatis sedangkan pada cahaya yang terang alat tidak dapat bekerja, karena itulah IC 4066 diganti dengan dioda empat kaki (D313) dan dikombinasikan dengan relay dan LDR. Setelah diujicobakan kembali ternyata alat dapat bekerja dengan baik. Bahkan diluar dugaan alat ini yang semula hanya dapat bekerja pada jarak antar sensor sebesar $13 \mathrm{~cm}$ tetapi dapat bekerja kurang lebih 2 meter dengan hanya mengubah sensornya sesuai jarak yang diinginkan. Semula sensor dibuat berbentuk $\mathrm{U}$, kemudian dimodifikasi sehingga sensornya dibuat saling berhadapan. Alat ini tidak hanya digunakan pada percobaan gerak parabola saja tetapi dapat pula pada percobaan gerak lurus berubah beraturan (GLBB) maupun gerak lurus beraturan (GLB).

Berdasarkan analisis data yang dilakukan, diperoleh grafik jarak terhadap waktu menunjukkan satu garis lurus dan juga grafik kecepatan terhadap waktu menunjukkan garis melengkung jadi diperoleh suatu hubungan antar variabel. Dari grafik diperoleh gradien atau tingkat kemiringan grafik sebesar 4,875 dan dari gradien tersebut dapat ditentukan percepatan gravitasi yaitu sebesar:

$$
\begin{aligned}
m & =\frac{1}{2} g \\
g & =2 m \\
g & =2 x 4,875=9,75 m / s^{2}
\end{aligned}
$$

Percepatan gravitasi $(g)$ yang dihasilkan hampir mendekati nilai 
percepatan gravitasi sebenarnya yaitu $9,8 \mathrm{~m} / \mathrm{s}^{2}$ mempunyai perbedaan hanya selisih 0,05 saja dari hasil penelitian. Ini membuktikan bahwa alat ini dapat bekerja dengan baik dan stopwatch dapat bekerja secara otomatis. Boleh dikatakan bahwa alat yang dibuat dan dirancang ini dapat digunakan untuk kegiatan percobaan gerak parabola.

\section{Simpulan dan Saran}

Hasil Penelitian ini menunjukkan bahwa alat percobaan gerak parabola dapat bekerja berdasarkan rangsangan cahaya. Stopwatch dapat bekerja secara otomatis ketika bola di tembakkan melewati sensor I pengukur waktu stopwatch mulai mencatat dan berhenti menghitung waktu pada saat bola melewati sensor II. Dari grafik dapat ditentukan gradien sebesar 4,875 dan gravitasi sebesar $9,75 \mathrm{~m} / \mathrm{s}^{2}$ yang nilainya mendekati angka percepatan gravitasi yang sebenarnya dalam tabel konstanta percepatan gravitasi yaitu $9,8 \mathrm{~m} / \mathrm{s}^{2}$. Alat ini diharapkan dapat bermanfaat untuk menunjang sarana dan prasarana untuk percobaan gerak parabola, gerak lurus beraturan (GLB), gerak lurus berubah beraturan (GLBB) serta aplikasinya pada tujuan kepentingan yang lainnya.

\section{Daftar Pustaka}

Amin M., 1988. Buku Pedoman Laboratorium dan Petunjuk Praktikum Pendidikan IPA Umum (General Science). Jakarta; Depdikbud, Dirjen Dikti Proyek LPTK.
Armitage E., 1982. Practical Physics in SI. London; Jhon Murray, Publishers Ltd 50 Albemarle Street

Cooper, William D, 1978. Electronic Instrumentation and Measurement Techniques, 2 ed. London; Prentice Hall Inc. N. J .

Faulkenberry, Luces M, 1982. An Introduction to Operational Amplifiers, with linier IC Application, 2 ed. Canada; John Willey \& Son Inc. Canada.

Giancoli, Douglas C, 1998. Fisika. Jakarta; Erlangga.

Malvino, Albert Paul, 1979. Electronic Principles, 2 ed. California; McGraw-Hill.

Sumisjo, Kartono, 1998. Elektronika Praktis, cetakan ke 8. Jakarta; Erlangga.

Sumual H., 1988. Penuntun Praktek Laboratorium Listrik, Jakarta; Depdikbud, Dirjen Dikti Proyek LPTK.

Soejoto dan Euis Sustini, 1993. Petunjuk Praktikum Fisika Dasar. Jakarta; Depdikbud, Dirjen Dikti Proyek Pembinaan TKPT.

Warsito, S, 1982. Sirkuit Arus Searah Seri Pelajaran Elektronik 1, cetakan ke 7. Jakarta; Karya Utama. 